\title{
Investigations into the Physicochemical Properties of Raw Edible Bird's Nest and Preparation of Double Boiled Soup
}

\author{
Phyu Phyu Win ${ }^{a}$, Myat Chaw Su ${ }^{b}$, Wint Yi Linn $c$, Yi Yi Myint ${ }^{*}$, Myo Myo Win* \\ adripphyuwin@gmail.com, \\ ${ }^{a}$ Chemical Technology Research Center, Department of Research and Innovation, Yangon, 11081, Myanmar \\ b Pharmaceutical Research Department, Department of Research and Innovation, Yangon, 11081, Myanmar \\ c Nanotechnology Research Department, Department of Research and Innovation, Yangon, 11081, Myanmar \\ * National Analytical Laboratory, Department of Research and Innovation, Yangon, 11081, Myanmar
}

\begin{abstract}
Edible bird nests (EBNs) are highly demanded globally and has long been used as a healthy food since ancient times. This study investigated the physicochemical properties of Myanmar EBN and preparation of EBN soup by double boiling technique. The protein content of Myanmar EBNs was found to be high value of 53.5\% $-59.3 \%$ which showed the good source of nutritional food. The protein content in EBN samples may differ due to the harvesting season, habitat and the diet of swiftlets. The moisture content was about $15.6 \%$. The mineral content (sodium, potassium, calcium, magnesium and zinc) was analyzed by AAS. The mineral contents in EBNs were found in the increasing order of $\mathrm{Zn}<\mathrm{K}<\mathrm{Mg}<\mathrm{Na}<\mathrm{Ca}$. The calcium $(0.71 \%)$ and magnesium $(361.3 \mathrm{ppm})$ contents were in a satisfactory level for consumers. After soaking the EBNs, the nitrate and nitrite contents in the soaking water were found to be $0.27 \mathrm{ppm}$ and $4.0 \mathrm{ppm}$ respectively and the values are low level. The nitrite level in Myanmar edible bird's nests may be safe for consumption. The EBN soup was prepared by double boiling method which was suitable to maintain its functional biological properties and the best cooking time was found within a period of two hour at $90^{\circ} \mathrm{C}$. The important factors are raw EBN quality, cooking time and cooking temperature to maintain the texture and nutritional values in soup. If the temperature may be too high or the time of cooking is too long protein content was destroyed because of the exceedingly high temperature. The investigation results in this study will be beneficial for the researchers, scientists, EBN manufactures and nutraceutical industries in Myanmar.
\end{abstract}

Published by IJRP.ORG. Selection and/or peer-review under responsibility of International Journal of Research Publications (IJRP.ORG)

Keywords: Edible bird nest, physiochemical properties, protein, double boiling;

\section{Introduction}

Edible bird nest (EBN) is the most highly valued health food products of South East Asia. Today the global edible birds nest industry is estimated to be worth $\$ 5$ billion, most of it produced in Southeast Asia. There are more than 24 species of insectivorous, ecolocating swiftlets around the world. Among them, a few produce nests that are edible. In Myanmar, the EBN is produced from Aerodromus fuciphagu and it is constructed from the salivary glands of swiftlet during nesting and breeding season. Nests are normally harvested three or four times a year. EBNs are graded according to the location where the nests are built, edibility, external features, colour, quality and cleanliness. There are several types of EBN such as cave nest, house nest, blood nest, white nest, yellow nest and orange nest as shown in Fig. 1. The colour, quality and grade of bird nests depend on the breeding sites, environmental condition and natural resources. By the contamination of nitrate and nitrite may cause the redness of EBN due to the fermentation process of bird soil guano and environmental resources. The cave EBN gives higher content of the minerals, a slightly yellowish to reddish or darker coloured compared to the house EBN. 
More than half of the bird nest compose with a high-protein glutinous material. EBN contains mainly carbohydrates, protein and mineral compounds. The sialic acid rich glycoproteins may benefit the neurological and intellectual capacity of infants. The composition of EBN makes it esteemed as a nutritional food and the nests are rich in nutrients such as protein, and are traditionally believed to provide health benefits as it is high in medical values with properties of anti-aging, anti-cancer, immune-enhancing, dissolving phlegm, suppressing cough and others. Some previous studies indicate that bird nest soup has the highest antioxidant and antihypertensive activities compared to chicken and fish soups.

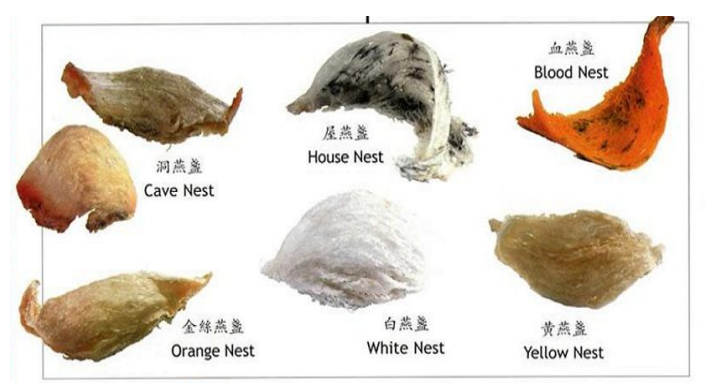

Fig. 1. Different types of bird nest

The swiftlet species: Aerodromus fuciphagus found in Myanmar is edible and has high nutritional value. However, there is no scientific research paper to investigate the quality and properties of Myanmar Edible Bird's Nest as well as quality control of bird nest soup processing. The most common eaten form of EBN is the soup. There are several factors for preparation of the bird nest soup from EBN which are water used, cooking temperature, cooking time, personal hygiene and methodology to maintain the texture and nutritional values. Therefore, this research work aims to investigate the physiochemical properties of raw Edible Bird's Nest (EBN) and EBN soup prepared by double boiling method. In this research work, the clean EBN was used as starting raw material.

\section{Materials and Method}

\subsection{Raw Materials and Reagents}

Clean edible bird nest was supported by Myike Nature Bird Nest Co., Ltd. The raw EBNs were stored in air tight plastic bag and kept at ambient temperature for physicochemical analysis. All other chemicals and reagents used were of analytical grades and used without further purification.

\subsection{Determination of Physicochemical Properties of Raw EBN}

The EBN raw material was grounded by using planetary ball mill for $5 \mathrm{sec}$. Then the grounded EBN powder was used to determine the $\mathrm{pH}$, moisture, protein, nitrate, nitrite and mineral contents present the EBN sample. To identify the main compounds present in the EBNs, the Fourier transform infrared spectroscopy (FTIR) was utilized by analyzing the absorption bands from $4000-600 \mathrm{~cm}^{-1}$ region. 


\subsubsection{Moisture Content}

The moisture content of EBN powder was measured by moisture analyzer. The ground EBN sample was weighed and was placed in the moisture analyzer at $105^{\circ} \mathrm{C}$. The moisture content (\%) measured by the analyzer was recorded.

\subsubsection{Protein Content}

The protein content of EBN powder was determined by Kjeldahl's method by using Association of Official Analytical Chemistry methods at National Analytical Laboratory.

\subsubsection{Elemental Analysis}

Mineral contents such as sodium, potassium, calcium, magnesium and zinc of EBN powder sample were determined by Atomic Absorption Spectrometer (AAS) at National Analytical Laboratory.

\subsubsection{Nitrate and Nitrite Analysis}

After soaking the clean EBNs, the nitrite and nitrate contents in the filtrate were determined by spectrophotometer in order to know the contamination of nitrate level in EBN.

\subsubsection{Fourier Transform Infrared Spectroscopy (FTIR) Analysis}

To determine quality and the functional groups of the main compounds present in the EBN sample, the FTIR spectroscopy was used by assigning the covalent bonds and fingerprint of the compound presents. The sample was identified by FTIR spectroscopy in the region $4000-600 \mathrm{~cm}^{-1}$. This method is useful for adulteration detection and quantification in various food products.

\subsubsection{Processing the EBN soup}

The EBN soup was prepared by slower and gentle heating process like the double boiling method at $90^{\circ} \mathrm{C}$ and then was autoclaved for sterilization at different temperatures. Firstly, $6.0 \mathrm{~g}$ of the nest were soaked in pure water for 4 hour until softened and removed small feathers and fine plumage by tweezers. Then the softened bird nest was rinsed and drained. The soaked bird nest was weighed to calculate the expansion percentage. The soaked bird nest was placed in an inner stewing pot adding $170 \mathrm{ml}$ of water and covered with lid. stewing pot was placed inside a larger pot such as a slow cooker. The time for double boiling was about two hour. $4.5 \mathrm{~g}$ of rock sugar was dissolved in sterile distilled water. When the bird's nest was cooked to desired texture, the rock sugar solution was added and covered for about $5 \mathrm{~min}$ to allow the sugar to dissolve fully as shown in Fig. 2. Then the pot was cooled at room temperature. The bird's nest soup was put in bottles and steam-sterilized in autoclave. Finally, the EBN soup was served or chilled. 


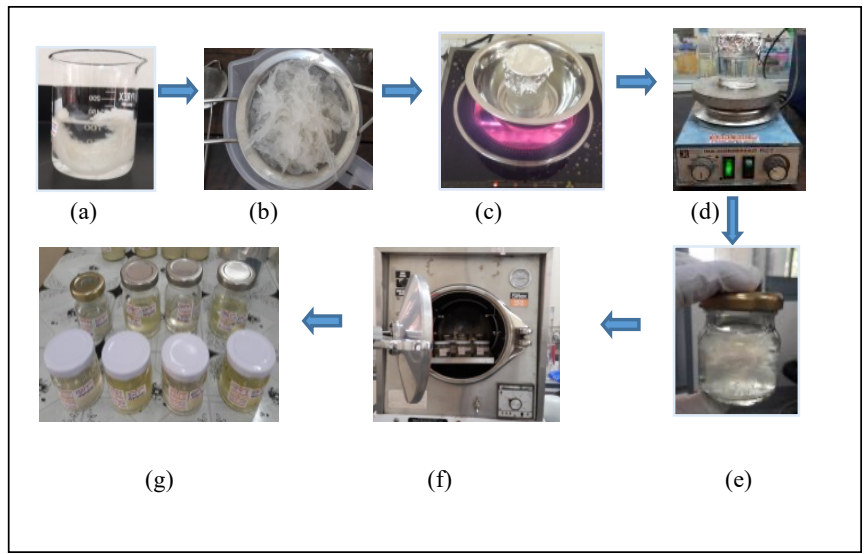

Fig. 2. Preparation of EBN soup by double boiling method (a) EBN soaking condition (b) Soaked EBN after removing small feathers and fine plumage (c) Double boiled cooking (d) Rock sugar sterile solution (e) The mixture of EBN and sugar solution (f)

Autoclave Sterilization of EBN soup (g) Ready-made EBN soup

3. Results and Discussion

The EBN powder for determination of physicochemical properties and for FTIR analysis was prepared by planetary ball mill and the size of the EBN powder was found to be $200 \mathrm{~nm}$ measured by Horiba SZ-100 as shown in Fig. 3.

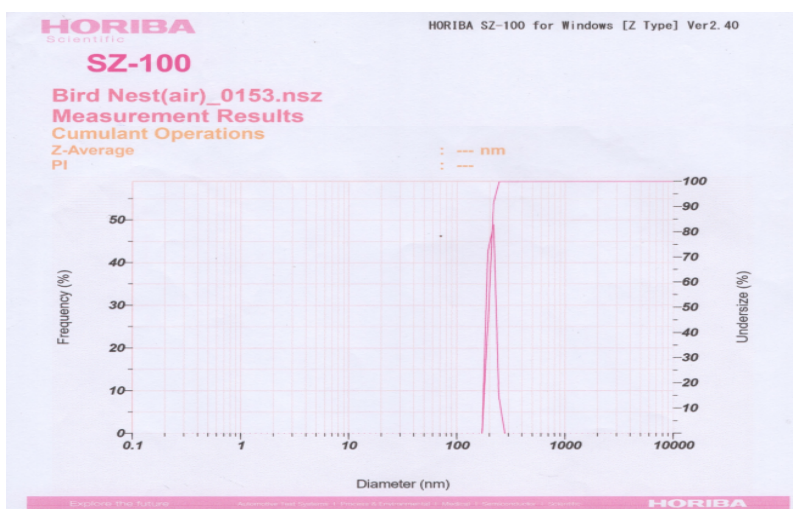

Fig. 3. Particle size of the EBN powder measured by SZ-100

\subsection{Physicochemical Properties of the EBN}

The physicochemical properties of the raw edible bird's nest are shown in Table 1. In this study the protein content in the EBN was found to be $53.5 \%-59.3 \%$ depended on the quality of bird nest. The moisture content of EBN powder was $15.6 \%$ and $\mathrm{pH}$ value was found to be 6.84-6.95. The expansion percentage of $\mathrm{EBN}$ in water at room temperature was found to be $750 \%$ based on dry sample. 
Table 1. Physicochemical properties of Myanmar edible bird's nest

\begin{tabular}{lc}
\hline Properties & Concentration \\
\hline $\mathrm{pH}$ & $6.84-6.95$ \\
Moisture & $15.6 \%$ \\
Protein & $53.5-59.3 \%$ \\
Nitrate Nitrogen as $\mathrm{NO}_{3}$ & $4.0 \mathrm{ppm}$ \\
Nitrite Nitrogen as $\mathrm{NO}_{2}$ & $0.27 \mathrm{ppm}$ \\
Expansion percentage & $750 \%$ \\
\hline
\end{tabular}

Myanmar EBN was found to be high protein content about $53.5 \%-59.3 \%$. The result shows that it is the good source of protein for health benefits. The protein content in EBN samples may differ due to the harvesting season, habitat, and the diet of swiftlets.

Pure bird's nest contains a small amount of nitrite which can be dissolved in water. After soaking the bird's nest, nitrite content will be reduced in the soaked EBN by dissolving out into the water. After soaking the bird nest, the filtrate water contains nitrite impurities and bacteria, so it is recommended to pour the water away after the bird's nest is expanded and softened. The nitrite and nitrate contents in the filtrate water were found to be $0.27 \mathrm{ppm}$ and $4.0 \mathrm{ppm}$ respectively and the values are low level. The nitrite level in edible bird's nests may be low and therefore it may cause the EBN to be whitish colour and safe for consumption. The nitrite contaminations in edible bird's nests may cause the redness of EBN by the natural environment resources.

\subsection{Mineral Analysis}

The mineral contents of the EBNs may be affected by the environmental condition of breeding sites. The mineral contents of edible bird's nest may be different in the limestone caves and house farms. The mineral content (sodium, potassium, calcium, magnesium and zinc) was analyzed by AAS and the result was shown in Table 2. The calcium (0.71\%) and magnesium (361.3 ppm) contents from EBN suggests that EBN is safe for consumption. The lower content of zinc was investigated and the mineral content in EBNs can be arranged in the increasing order of $\mathrm{Zn}<\mathrm{K}<\mathrm{Mg}<\mathrm{Na}<\mathrm{Ca}$.

Table 2. Mineral content of Myanmar EBN

\begin{tabular}{ll}
\hline Type of Mineral & Content \\
\hline Sodium $(\mathrm{Na})$ & $0.17 \%$ \\
Potassium $(\mathrm{K})$ & $237.1 \mathrm{ppm}$ \\
Calcium $(\mathrm{Ca})$ & $0.71 \%$ \\
Magnesium $(\mathrm{Mg})$ & $361.3 \mathrm{ppm}$ \\
Zinc $(\mathrm{Zn})$ & $12.3 \mathrm{ppm}$ \\
\hline
\end{tabular}

\subsection{FTIR analysis}

The functional groups of the compounds present in EBN were identified by the FTIR spectrometer. This study was carried out to discriminate the EBN and its' potential adulterants through the EBN fingerprint using the FTIR analysis. The results and assignment of absorption bands are shown in Table 3 . In this study, major 
bands can be observed resulting from protein at $1631.35 \mathrm{~cm}^{-1}$ and $1542.02 \mathrm{~cm}^{-1}$, carbohydrate at $1033.59 \mathrm{~cm}^{-1}$ . These bands confirmed for the presence of protein and carbohydrates in the EBN samples. The contamination of calcium carbonate was found by the two weak bands at $1410 \mathrm{~cm}^{-1}$ and $873 \mathrm{~cm}^{-1}$ due to the carbonate functional groups. The FTIR spectrum was shown in Fig. 4.

Table 4. The assignment of FTIR absorption bands of EBNs

\begin{tabular}{lll}
\hline Wave Number $\left(\mathrm{cm}^{-1}\right)$ & Assignment & Results \\
\hline 3275.87 & $\mathrm{C}=\mathrm{O}$ Stretching of primary amine & Protein \\
1631.35 & $\mathrm{~N}-\mathrm{H}$ bending of secondary amine & Protein \\
1542.02 & $\mathrm{~N}-\mathrm{H}$ bending of secondary amine & Protein \\
1523.06 & C-O stretching or C-C stretching & Protein \\
1032.22 & Carbohydrate
\end{tabular}

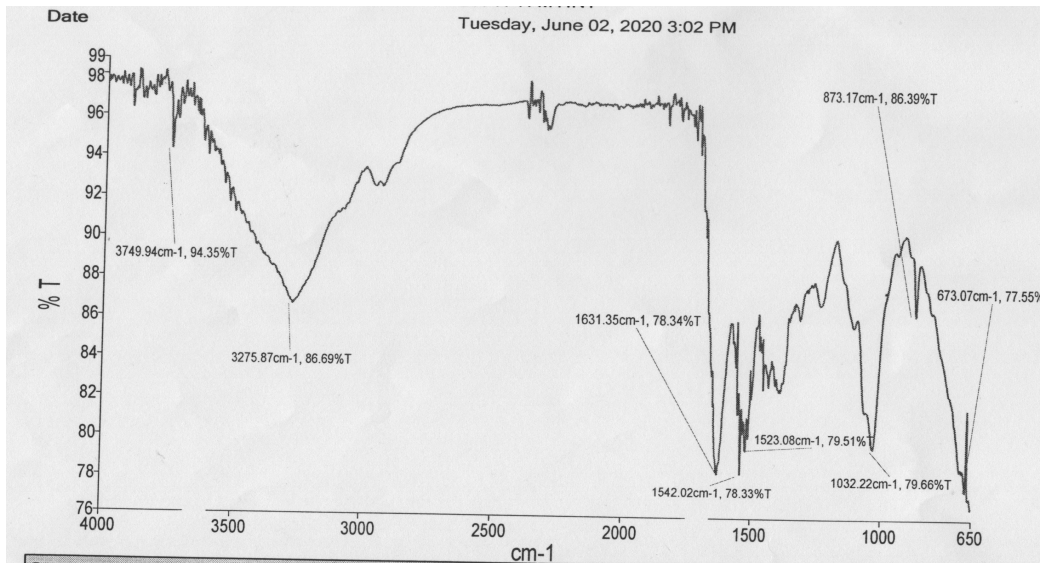

Fig. 4. FTIR spectrum of Myanmar Raw EBN

\subsection{Preparation of EBN Soup}

The important factors for preparation of the 'bird's nest soup' are water used, cooking temperature, cooking time, personal hygiene and method to maintain the health benefits. This technique is to achieve the maximum extraction of flavour with little compromise to the flavour or texture of the ingredients used. Edible bird's nest is rich in more than 50\% glycoproteins and the texture and quality of ingredients in 'bird's nest soup' should be maintained.

Therefore, the preparation of EBN soup was conducted by heating slowly and gently till $80^{\circ} \mathrm{C}$ to $90^{\circ} \mathrm{C}$. Double-boiling of the EBNs may not kill all the nest-associated bacteria and then the EBN soup bottles were steam sterilized. If the temperature may be too high or the time of cooking is too long, protein content is destroyed because of the exceedingly high temperature. In this study, the best cooking time was found within a period of two hour at $90^{\circ} \mathrm{C}$ and its functional biological properties are retained. 


\section{Conclusions}

Myanmar EBN was found to be high protein content about 59.3\% and it showed the good source of protein for health benefits. Low nitrate and nitrite level of Myanmar EBNs may appear whitish colour and it shows its safety and quality for consumption. The mineral contents in EBNs were found in the increasing order of $\mathrm{Zn}<\mathrm{K}<\mathrm{Mg}<\mathrm{Na}<\mathrm{Ca}$. The mineral contents such as calcium and magnesium are low level compared with EBNs in other countries. The effect of heating condition for preparation of bird nest soup is very important on texture and protein content. Therefore, the double -chamber method was suitable to maintain its functional biological properties and the best cooking time was found within a period of two hour at $90^{\circ} \mathrm{C}$. Further studies will be conducted the effect of cooking temperature and time on the protein hydrolysis antioxidant activities of EBN soup in different range as well as the content of silicylic acid in Myanmar EBNs.

\section{References}

[1] Hamzal et al, 2013. "Nutritional properties of edible bird nest", J Asian Sci Res, Vol. 3, pp. 600-607

[2] Lee Ting Hun, and et. al, 2015. "Investigations into the physicochemical, biochemical and antibacterial properties of Edible Bird's Nest", Journal of Chemical and Pharmaceutical Research, 7(7):228-247.

[3] Meei Chien Quek and et. al, 2015. "Preliminary nitrite, nitrate and colour analysis of Malaysian edible bird's nest", INFORMATION PROCESSING IN AGRICULTURE 2, pp. 1-5.

[4] MF Marcone, 2005. "Characterization of the edible bird's nest the "Caviar of the East" Food Res. Int., 38(10), pp. 1125-1134.

[5] Nur'Aliah Daud and et. al, 2019. "Edible Bird's Nest: Physicochemical Properties, Production, and Application of Bioactive Extracts and Glycopeptides" Food Reviews International, DOI: 10. 10.1080/87559129.2019.1696359, pp. 1-20.

[6] Nurfatin Mohd Halimi, Zalifah Mohd Kasim, and Abdul Salam Babji, 2014. "Nutritional composition and solubility of edible bird nest (Aerodramus fuchiphagus)" AIP Conference Proceedings 1614, 476, https://doi.org/10.1063/1.4895243.

[7] Wong, S.F., Lim, P.K.C., Mak, J.W., Ooi, S.S. and Chen, D.K.F, 2018. "Molecular characterization of culturable bacteria in raw and commercial edible bird nests (EBNs)" International Food Research Journal 25(3): pp. 966-974. 